\title{
O USO DAS ESTRATÉGIAS DE CO-MARKETING, COOPETIÇÃO E MARKETING DO DESTINO, POR MEIO DA MÍDIA SOCIAL INSTAGRAM NO PERÍODO DE PANDEMIA
}

\author{
André Riani Costa Perinotto \\ Doutor em Ciências da Comunicação \\ UFDPar (Universidade Federal do Delta do Parnaíba) e UECE \\ perinotto@ufpi.edu.br \\ Luciano de Lima Sobrinho \\ Especialista em Engenharia de Produção pela UCM-RJ \\ IFCE e UECE \\ 11lsobrinho@gmail.com \\ Jakson Renner Rodrigues Soares \\ Doutor em Planejamento do Turismo \\ Universidad da Coruña (Espanha) e UECE \\ jakson.soares@udc.gal \\ María Dolores Sánchez Fernandéz \\ Doutora em Competitividade, inovação e desenvolvimento \\ Universidad da Coruña (Espanha) \\ maria.sanchezf@udc.es
}

\section{Resumo}

Objetivo do estudo: Com o surgimento do vírus Covid-19, medidas de prevenção para controlar seu avanço foram tomadas por todo o mundo, acarretando impactos significativos no setor turístico e obrigando as empresas a replanejarem suas ações. Neste artigo buscou-se identificar de que forma os meios de hospedagem em atuação no destino turístico de Jericoacoara têm realizado marketing digital durante a pandemia, descobrindo se existem estratégias de gestão Co-Marketing e Coopetição.

Metodologia/abordagem: Para tanto, utilizou-se para isso a metodologia de trabalho com imersão na internet com cunho qualitativo.

Originalidade/Relevância: É relevante neste momento de recuperação pensar em estratégias coletivas entre as empresas com possíveis realizações de parcerias para divulgação dos produtos e/ou serviços, como o co-marketing e a coopetição.

Principais resultados: Entende-se como a primeira tomada de decisão importante, a busca por inovação no uso das Tecnologias de Informação e Comunicação para realização do marketing digital, para mantimento do relacionamento com os clientes, sabendo que o contato físico se encontra proibido. Encontrou-se que, as estratégias de co-marketing e coopetição são realizadas, porém em escala bem reduzida, diferente do marketing de destino que já é utilizado como ação por parte dos estabelecimentos em Jijoca de Jericoacoara-Ceará.

Contribuições teóricas/metodológicas: Discussão e apresentação de coopetição e co-marketing para estudos no turismo em tempos que o mercado pede por soluções rápidas e eficazes em destinações por vezes afetadas pela baixa demanda turística.

Palavras-chave: Marketing digital. Co-marketing. Coopetição. Marketing de destino.

Cite como

American Psychological Association (APA)

Perinotto, A. R. C., Lima Sobrinho, L. de. Soares, J. R. R., \& Sánchez Fernandéz, M. D. (2021, maio/ago.). O uso das estratégias de Comarketing, Coopetição e marketing do destino, por meio da mídia social Instagram no período de pandemia. PODIUM Sport, Leisure and Tourism Review, São Paulo, 10(2), 81-105. https://doi.org/10.5585/podium.v10i2.19018. 
Perinotto, A. R. C., Lima Sobrinho, L. de. Soares, J. R. R., \& Sánchez Fernandéz, M. D. (2021, maio/ago.). O uso das estratégias de Co-marketing, Coopetição e marketing do destino, por meio da mídia social Instagram no período de pandemia

\title{
THE USE OF CO-MARKETING STRATEGIES, COOPETITION AND DESTINATION MARKETING THROUGH SOCIAL MEDIA INSTAGRAM IN PANDEMIC PERIOD
}

\begin{abstract}
Objective of the study: With the emergence of the Covid-19 virus, preventive measures to control its progress have been taken worldwide, causing significant impacts on the tourism sector and forcing companies to replan their actions. In this article we sought to identify how the lodging facilities operating in the tourist destination of Jericoacoara have been conducting digital marketing during the pandemic, discovering if there are management strategies Co-Marketing and Coopetition.

Methodology / approach: To this end, we used the methodology of work with immersion in the internet with a qualitative nature.

Originality/Relevance: It is relevant in this moment of recovery to think about collective strategies between companies with possible realizations of partnerships for the dissemination of products and / or services, such as co-marketing and coopetition.

Main results: It is understood as the first important decision making, the search for innovation in the use of Information and Communication Technologies to carry out digital marketing, to maintain the relationship with customers, knowing that physical contact is prohibited. It was found that the comarketing and coopetition strategies are carried out, but on a very small scale, different from the destination marketing that is already used as an action by the establishments in Jijoca de JericoacoaraCeará.

Theoretical/methodological contributions: Discussion and presentation of coopetition and comarketing for studies in tourism in times when the market asks for quick and effective solutions in destinations sometimes affected by low tourist demand.
\end{abstract}

Keyword: Digital marketing. Co-marketing. Coopetition. Destination marketing.

\section{EL USO DE ESTRATEGIAS DE MARKETING CONJUNTO COOPERACIÓN Y MARKETING DE DESTINOS, A TRAVÉS DE LAS REDES SOCIALES INSTAGRAM EN EL PERÍODO DE LA PANDEMIA}

\section{Resumen}

Objetivo del estudio: Con la aparición del virus Covid-19, se han tomado medidas preventivas para controlar su avance en todo el mundo, provocando importantes impactos en el sector turístico y obligando a las empresas a replantear sus acciones. En este artículo intentamos identificar cómo las instalaciones de hospedaje que operan en el destino turístico de Jericoacoara han estado realizando marketing digital durante la pandemia, descubriendo si existen estrategias de gestión de Co-Marketing y Coopetición.

Metodología / enfoque: Para ello se utilizó la metodología de trabajo con inmersión en internet de carácter cualitativo.

Originalidad/Relevancia: Es relevante en este momento de recuperación pensar en estrategias colectivas entre empresas con posibles realizaciones de alianzas para la difusión de productos y / o servicios, como el co-marketing y la cooperación.

Principales resultados: Se entiende como la primera toma de decisiones importantes, la búsqueda de la innovación en el uso de las Tecnologías de la Información y la Comunicación para realizar marketing digital, para mantener la relación con los clientes, sabiendo que el contacto físico está prohibido. Se constató que las estrategias de co-marketing y coopetición se llevan a cabo, pero a muy pequeña escala, diferente al marketing de destino que ya es utilizado como acción por los establecimientos de Jijoca de Jericoacoara-Ceará. 
Perinotto, A. R. C., Lima Sobrinho, L. de. Soares, J. R. R., \& Sánchez Fernandéz, M. D. (2021, maio/ago.). O uso das estratégias de Co-marketing, Coopetição e marketing do destino, por meio da mídia social Instagram no período de pandemia

Aportes teóricos/metodológicos: Discusión y presentación de la coopetición y el co-marketing para estudios en turismo en tiempos en los que el mercado pide soluciones rápidas y efectivas en destinos en ocasiones afectados por baja demanda turística.

Palabras clave: Marketing digital. Co-marketing. Coopetición. Marketing de destino.

\section{Introdução}

Devido ao momento de pandemia que a população mundial vive, não é de se surpreender com os resultados encontrados acerca dos estudos relacionados aos impactos que o turismo está sofrendo em todo o mundo. Como era de se esperar, com isolamento social, as restrições ao deslocamento e outras imposições para contenção do avanço do vírus, o turismo, que é uma atividade caracterizada pelo deslocamento das pessoas, sofreria um enorme impacto ao longo de toda sua cadeia produtiva e em todos os segmentos.

Tanto para empresas consolidadas no mercado como para empreendimentos que estavam na iminência de iniciarem seus trabalhos no setor turístico, faz-se necessário repensarem o momento, de maneira a planejar e preparar o retorno quando tudo passar. Com isso, diante do cenário de impossibilidade de relacionamentos físicos com clientes, os prestadores de serviços precisam se reinventar, inovar e/ou intensificar o uso das mídias sociais para se relacionar com seus clientes atuais e potenciais durante a pandemia. Uma vantagem das redes sociais é que com elas existe certa interação entre pessoas e entre negócios, sem a necessidade da presencialidade física (Alves, Costa e Perinotto, 2017). Assim, entende-se, portanto, que não é porque a situação atual, derivada da pandemia, impossibilita o contato físico que a isto vai debilitar a comunicação das empresas, o que para uns é um obstáculo, para outros é uma oportunidade.

Deste modo, muitos foram os estudos que destacaram a importância de uma comunicação fluída na gestão de uma crise como essa (Costa-Sánchez e López-García, 2020; Xifra, 2020; Ferrer-Serrano; Latorre-Martínez y Lozano-Blasco, 2020; Huertas, Oliveira e Girotto, 2020). Costa-Sánchez e López-García (2020) estudaram a comunicação por meio da cobertura jornalística. Por outro lado, Xifra (2020) investigou como a crise da pandemia da Covid-19 afeta a prática da comunicação corporativa. Já Ferrer-Serrano; Latorre-Martínez e Lozano-Blasco (2020) focaram no papel de Twitter na comunicação das universidades espanholas. Ainda, se aproximando mais ao turismo Huertas, Oliveira e Girotto (2020) analisaram a estratégia comunicativa de Oficinas Nacionais de Turismo em Espanha e Itália. 
Perinotto, A. R. C., Lima Sobrinho, L. de. Soares, J. R. R., \& Sánchez Fernandéz, M. D. (2021, maio/ago.). O uso das estratégias de Co-marketing, Coopetição e marketing do destino, por meio da mídia social Instagram no período de pandemia

Também se encontra um estudo sobre como os turistas utilizam as redes sociais para se comunicar e buscaram informações em um momento de crise como esta (Park, Kim e Choi, 2019). Porém, existe uma lacuna em como as empresas turísticas se comunicam durante uma crise sanitária, como a da COVID-19, principalmente tomando como referência estratégias de coopetição e co-marketing.

Diante disto, a área estudada foi Jijoca de Jericoacoara no Ceará que foi distinguida como Área de Proteção Ambiental (APA) em 1984 nos municípios de Jijoca de Jericoacoara/CE e Cruz/CE. Em fevereiro de 2002, um decreto federal redesenhou os limites dessa área, limitando sua extensão em 8.416,08 hectares como Parque Nacional de Jericoacoara. Assim sendo, tanto a APA quanto o Parque Nacional de Jericoacoara demandam atenção para o desenvolvimento do espaço, estimulando o desenvolvimento sustentável (Buosi e Silva, 2013). Alusivo ao turismo, Jericoacoara possui fluxo de visitantes ao longo de todo o ano, com períodos distinguidos como alta estação (janeiro, junho, julho e dezembro), e ocasiões com circulação específica de europeus (abril, maio, agosto, setembro e outubro) (Buosi e Silva, 2013).

Ainda, em uma tentativa de caracterizar a demanda do destino Jericoacoara, que segundo Meira et. al. (2017, p. 9):

Através da análise das questões relacionadas aos aspectos demográficos dos respondentes da presente investigação, pode-se perceber que os turistas que visitam o destino de Jericoacoara/CE são na sua maioria, brasileiros, jovens, com nível superior de escolaridade, que permanecem por pouco tempo no destino e de classe social B - segundo dados do IBGE (2016) - ou seja, que recebem entre 03 e 11 salários mínimos. Quanto à satisfação dos mesmos, pode-se perceber que os atributos voltados aos atrativos naturais, hospedagem e alimentação foram melhores avaliados. Todavia, apenas os atrativos naturais e a alimentação influenciam na intenção de retorno dos turistas.

Para tanto, ao avaliar a situação atual em meio a uma pandemia e planejar suas ações, as prestadoras de serviços necessitam refletir e perceber que não estão isoladas e existem mais empresas no destino, não pensando somente na própria empresa, mas que seus esforços devem ser alocados em torno deste marketing digital para o destino como um todo. Ou como destacam Soares, Gabriel e Perinotto (2019) é necessário trabalho em conjunto entre as organizações, tanto públicos quanto privados, para fortalecer a imagem dos destinos e melhorar a sua atratividade. Um destino se fortalece quando existem esforços de seus agentes-atores para que juntos criem estratégias e ações em conjunto enquanto destino turístico.

A partir disto, pensar de maneira macro, em que o foco inicial do marketing seja o destino turístico, deste modo surgem as estratégias de gestão como o Co-Marketing e a 
Perinotto, A. R. C., Lima Sobrinho, L. de. Soares, J. R. R., \& Sánchez Fernandéz, M. D. (2021, maio/ago.). O uso das estratégias de Co-marketing, Coopetição e marketing do destino, por meio da mídia social Instagram no período de pandemia

Coopetição entre as empresas turísticas do destino. Ambas estratégias são voltadas para o foco da cooperação entre empresas, concorrentes ou não, no desenvolvimento de um produto e/ou serviços. Como destaca Toledo, Valdes e Polero (2002) os stakeholders trabalhem juntos estratégias competitivas do destino e colaborativas entre si no turismo, para que possam melhorar a competitividade do próprio destino turístico.

Deste modo, questiona-se como se dá a coopetição e co-marketing por meio do marketing digital entre as empresas turísticas de um dos principais destinos turísticos do Nordeste brasileiro? Assim, pensando na sobrevivência e competição do destino turístico em meio a uma pandemia.

Para tanto, este trabalho tem como objetivo identificar a existência de estratégias de comarketing e coopetição no Instagram pelos meios de hospedagem de Jericoacoara. Sua relevância está no fato dessas estratégias de gestão serem de grande importância para o atual momento que o turismo mundial vive, em que é importante a realização de trabalhos em conjunto, de cooperação entre empresas visando a reconstrução do turismo.

Soma-se a isto, a possibilidade futura destas estratégias serem usadas por empreendimentos a serem implantados nos municípios vizinhos a Jericoacoara, já que se pensa em absorver a demanda turística deste destino indutor. Sendo um trabalho científico, ressaltase também a importância da contribuição à literatura tratando dos conceitos que esse trabalho apresenta.

O procedimento metodológico adotado para essa investigação baseou-se inicialmente em pesquisas bibliográficas sobre os conceitos em análise, em que complementarmente a essa revisão de literatura, realizou-se o método de pesquisa conhecido como netnografia, que busca estudar o comportamento das pessoas de maneira virtual (Alves, Costa e Perinotto, 2017). Sendo assim, foi utilizado da internet por meio da rede social Instagram, para verificação do uso dessas estratégias de gestão por parte de algumas empresas de meio de hospedagem do município de Jijoca de Jericoacoara, Ceará. É importante salientar o benefício da obtenção dos dados das redes sociais, considerando que os dados não são desvirtuados por interferência de um pesquisador, o que pode acontecer na pesquisa convencional (Torres, 2009).

Na seguinte seção se apresenta a situação do turismo no período de pandemia. A terceira seção apresenta as teorias relacionadas com o marketing digital e as estratégias coopetitivas. $\mathrm{Na}$ quarta seção se apresentam os passos metodológicos do estudo seguida dos resultados. $\mathrm{Na}$ última seção encontram-se as conclusões do estudo. 
Perinotto, A. R. C., Lima Sobrinho, L. de. Soares, J. R. R., \& Sánchez Fernandéz, M. D. (2021, maio/ago.). O uso das estratégias de Co-marketing, Coopetição e marketing do destino, por meio da mídia social Instagram no período de pandemia

\section{A situação do turismo em tempos de pandemia}

Tendo como base anos anteriores, em que o setor turístico em 2019 apontou mais um ano de crescimento, registrando o décimo consecutivo nessa escala (Mendonça, 2020), o ano de 2020 se iniciava com boas perspectivas, tendo como expectativa de crescimento a demanda por viagens e um consequente aumento do faturamento das empresas de diversas Atividades Características do Turismo (Barbosa, Coelho, Motta \& Guimarães, 2020).

Entretanto, nesse mesmo período, o mundo soube do surgimento de uma nova doença, tendo o crescimento do número de indivíduos contaminados ocorrendo de forma exponencial, forçando a Organização Mundial de Saúde (OMS) declarar o status de pandemia pelo coronavírus SARS-Cov-2, doença nomeada oficialmente como COVID-19 (Gama, 2020).

O novo vírus vem desafiando o mundo, levando a ciência em uma corrida contra o tempo na busca de uma vacina para sua prevenção, motivando a maioria dos países a reagirem temporariamente com intervenções não farmacêuticas para evitar o avanço da doença, incluindo bloqueio, distanciamento social, fechamento de escolas / universidades e empresas / locais de trabalho, cancelamento ou adiamento de eventos e proibições de reunir pessoas em determinados números (Gössling, Scott \& Hall, 2020). Com todas essas intervenções, a pandemia da COVID-19 não traz um impacto restrito à questão sanitária, mas também tem consequências importantes para política, economia, relações sociais, meio ambiente e turismo (Gama, 2020).

As restrições de viagens internacionais, regionais e locais afetaram imediatamente a economia, incluindo sistemas de turismo, fazendo com que tanto o turismo internacional quanto o doméstico declinassem vertiginosamente durante um período curto de semanas (Gössling et al., 2020). Para o Brasil, as medidas foram bastantes impactantes, tendo em vista que o país tem experimentado uma trajetória de crescimento do turismo tanto do ponto de vista doméstico como em número de chegadas internacionais, onde dados do IBGE, indicam que o turismo no país contribui, diretamente, para cerca de 3,7\% do PIB nacional e 3\% do total de empregos no país” (Barbosa et al., 2020, p. 8).

Entretanto, os números de diversos indicadores, que deveriam ser positivos para o turismo no ano de 2020, tiveram uma enorme queda a partir de meados do mês de março, período este em que muitos estados brasileiros iniciaram as medidas de isolamento social e suspensão de serviços não essenciais (Serviço Brasileiro de Apoio às Micro e Pequenas Empresas) (SEBRAE, 2020). 
Perinotto, A. R. C., Lima Sobrinho, L. de. Soares, J. R. R., \& Sánchez Fernandéz, M. D. (2021, maio/ago.). O uso das estratégias de Co-marketing, Coopetição e marketing do destino, por meio da mídia social Instagram no período de pandemia

Observando este cenário, percebe-se que não basta somente avaliar os impactos imediatos que o vírus trouxe ao mundo, mas sim iniciar estratégias de recuperação, visto que a profundidade e a complexidade do impacto da COVID-19 exigem uma reação de curto prazo e uma prontidão de longo prazo (Gretzel, Fuchs, Baggio, Hoepken, Law, Neidhardt, Pesonen, Zanker \& Xiang, 2020). Sendo assim, enquanto se busca solução financeira para evitar o colapso do setor, dentro do possível, deve-se voltar o olhar para a retomada dos negócios, tendo como regra básica para uma crise que foge ao controle das empresas, um replanejamento dos negócios o quanto antes (Barbosa et al., 2020). Esse replanejamento vai exigir das empresas e dos destinos já consolidados no mercado, a necessidade de se adaptarem para não caírem no esquecimento (Perinotto \& Siqueira, 2018) assim como os novos empreendimentos que pensavam em se projetar no mercado antes pandemia.

\section{TIC e marketing digital em tempos pandémicos}

A Organização Mundial do Turismo (OMT) já ressalta essa ideia de repensar os modelos de negócios, ao apresentar um quadro de análise SWOT sobre os desafios e oportunidades para o setor turístico e toda sua cadeia produtiva, citando a busca por inovação e digitalização (World Tourism Organization, 2020).

Sendo a atividade turística de grande relevância e complexidade, essa inovação e digitalização estão atreladas à Tecnologia da Informação e Comunicação (TIC), no qual tem papel preponderante no desenvolvimento e reestruturação do turismo, levando os agentes que fizerem uso da internet, ganharem em competitividade ao utilizar de novas possibilidades tecnológicas (Oliveira, n.d.) e das mídias sociais para atraírem seus antigos e novos clientes.

As TIC já vêm gerando um impacto profundo na indústria do turismo ao longo de anos, em que o acesso à internet e aos dispositivos de comunicação móvel aumentaram o número de relacionamento entre cliente e a indústria do turismo (Purohit, 2018), exigindo assim a modernização dos equipamentos, a virtualização da comunicação e a personalização dos produtos (Perinotto \& Siqueira, 2018). A internet ao revolucionar os meios de comunicação, as relações sociais e comercial, tornou-se um sistema de comunicação que se inova a cada dia e que proporciona uma interação mundial, facilitando o acesso às informações e assim, aos poucos certificando as empresas da necessidade de utilizar as mídias sociais (Gonçalves, 2012). Esta conscientização é muito significante para os dias de hoje, visto que o "atual cenário 
Perinotto, A. R. C., Lima Sobrinho, L. de. Soares, J. R. R., \& Sánchez Fernandéz, M. D. (2021, maio/ago.). O uso das estratégias de Co-marketing, Coopetição e marketing do destino, por meio da mídia social Instagram no período de pandemia

determina que seja estabelecido um relacionamento com o público e que seus interesses sejam despertados" (Lapolli, Amaral, Amaral, \& Gauthier, 2009, p. 22).

As mídias sociais vêm substituindo há algum tempo uma grande área da comunicação tradicional, tendo em algumas plataformas como Facebook, Twitter, LinkedIn e Instagram o meio de comunicação direta entre as empresas e seus usuários, permitindo que esses atores conversem diretamente entre si trocando valores (Purohit, 2018). Perinotto \& Siqueira (2018, p.4) mencionam que esta "troca como parte principal da definição de marketing fortalece o discurso de que o relacionamento com o cliente é o principal objetivo das estratégias de marketing. A busca por esse relacionamento se intensifica conforme a sociedade muda sua própria forma de se relacionar, levando as empresas a direcionarem seus esforços para o ambiente virtual, em que a maioria dos relacionamentos acontece atualmente".

Assim, com a evolução das mídias sociais, acabou-se trazendo diversos desafios para profissionais ligados à área de comunicação, despontando novos modos de realização de campanhas (Lapolli, 2009), como o marketing digital sendo realizado aliado ao marketing tradicional. Marketing digital, que conforme Pizeta, Severiano \& Fagundes (2016), é voltado para aplicação de estratégias de marketing às plataformas digitais como, redes sociais, sites e aplicativos, tendo como foco o desenvolvimento de estratégias de mercado via internet.

Gonçalves (2012) ressalta que essas mídias não foram inicialmente pensadas para o intuito do marketing, porém devido ao comportamento dos usuários dentro delas, percebeu-se ali um novo espaço para a atuação do marketing, atingindo assim proporções globais a um custo relativamente baixo. Sprandel (2009) complementa esse raciocínio quando comenta que:

O webmarketing então, permitiu que muitas empresas intensifiquem sua comunicação e seus relacionamentos, bem como as transações com seus consumidores. Esse novo aspecto da comunicação e do marketing com base na web altera a forma de como a comunicação começa ser feita, através de transmissão de conteúdos e de informações, no caso a comunicação de muitos-para-muitos que ocorre em um ambiente mediador, que no caso oferece a interatividade (Sprandel, 2009, p. 16).

E quando relacionado diretamente ao turismo, "os métodos de marketing digital revolucionaram a indústria de turismo e viagens de várias maneiras” (Purohit, 2018, p.2), em que Gonçalves (2012) reforça que as mídias sociais foram relevantes, visto ser um canal de informação-intensiva devido aos consumidores poderem obter muitas informações que os auxiliam no planejamento e tomada de decisão de suas viagens. 
Perinotto, A. R. C., Lima Sobrinho, L. de. Soares, J. R. R., \& Sánchez Fernandéz, M. D. (2021, maio/ago.). O uso das estratégias de Co-marketing, Coopetição e marketing do destino, por meio da mídia social Instagram no período de pandemia

Atualmente tem-se inúmeras possibilidades de redes sociais digitais para realização de marketing digital, em que se pode destacar o Instagram, que segundo Imme (2020), se encontra como a quarta mídia social mais popular no Brasil e que possui um crescimento elevado no número de usuários. O Instagram é uma rede social que permite o compartilhamento de fotos e vídeos, e que apesar de ser criado inicialmente para aparelhos mobile, hoje existe a possibilidade de acesso via computador (Lichtenheld, 2018). O aplicativo teve sua criação realizada em parceria entre os engenheiros de software Michel Kierg e Kevin Systrom que o fizeram a partir da simplificação de um outro aplicativo desenvolvido por eles. O Burbn (Sampaio, 2013), em que além dos efeitos básicos gratuitos de tirar fotos, escolher filtros e compartilhar o resultado nas redes sociais, possibilita que cada usuário além de seguir, curta, comente e compartilhe as imagens postadas por outros usuários (Perinotto \& Siqueira, 2018).

O aplicativo já passou por diversas atualizações e modificações, na qual vale comentar a ocorrida no dia 2 de maio de 2013 quando o aplicativo adiciona um recurso oficial para marcação de pessoas nas fotos (Sampaio, 2013). Com esta funcionalidade, além do usuário marcado na foto receber a foto em seu perfil, os seguidores do perfil que publicou a foto, visualizam este usuário marcado, podendo acessar diretamente seu perfil. Esta percepção é reforçada por Lichtenheld (2018) ao dizer que devido a crescente popularidade e alcance tão elevado, o Instagram tem sido muito utilizado pelas empresas como forma de fomentar o relacionamento com seus clientes, visto que o compartilhamento de fotos é um dos meios mais eficazes no que diz respeito a atrair a atenção do consumidor, permitindo a possibilidade de interação entre empresas e consumidores, e entre os próprios consumidores.

Percebe-se nesta funcionalidade uma possibilidade de co-marketing ou coopetição quando um usuário faz a "marcação" de outros empreendimentos.

\subsection{Co-Marketing e Coopetição}

Com todo o avanço das TIC e sua importância para as empresas do setor turístico, observa-se neste momento de isolamento social que as empresas não podem atender seus clientes presencialmente, a principal estratégia para todo e qualquer empreendimento está no marketing digital, realizando um esforço grande para incentivar a demanda turística para o momento pós pandemia (Barbosa et al., 2020). Entretanto é importante que os empreendimentos não visualizem um trabalho de marketing no mercado visando uma competição ambiciosa na busca de crescimento e enriquecimento individual, mas sim é 
Perinotto, A. R. C., Lima Sobrinho, L. de. Soares, J. R. R., \& Sánchez Fernandéz, M. D. (2021, maio/ago.). O uso das estratégias de Co-marketing, Coopetição e marketing do destino, por meio da mídia social Instagram no período de pandemia

necessário se buscar uma união setorial entre os empresários, com entidades de classe e representantes locais, regionais e nacionais visando a recuperação não só de seu empreendimento, mas principalmente do destino turístico, sendo este, um momento de união pela reconstrução do turismo (Barbosa et al., 2020).

Essa mudança de paradigma de estratégia de mercado já vem acontecendo a algum tempo e Gollo (2005, citado por Merofa \& Bueno, 2009), comenta que:

O processo de globalização tem transformado o paradigma da competição e feito com que as organizações evoluam dentro de um ambiente complexo e dinâmico marcado pelas incertezas e mudanças constantes, exigindo delas maior velocidade para criar vantagens competitivas e alteração do modelo mecanicista e de inovação linear, endógena e isolada, para um modelo estratégico orgânico e relacional (Merofa \& Bueno, 2009, p. 7).

Ressalta-se assim, o importante momento de as empresas não pensarem somente na competição para ganharem clientes, mas sim também na cooperação que pode ser realizada entre elas, entendendo que esta ação num ambiente competitivo é considerada uma resposta natural e uma importante estratégia que pode ser utilizada para uma reconstrução mais integradora do destino turístico (Fumi Chim-Miki \& Batista-Canino, 2016). Este ambiente de busca conjunta pela reestruturação do destino, é destacado por Wang e Krokover (2008) ao informar que:

a fragmentação da indústria do turismo e a complexidade do marketing de destino exigem uma abordagem coletiva do marketing de destino, e como a indústria do turismo em um destino mantém o equilíbrio entre cooperação e a competição, determina em grande medida a eficácia de seus esforços de marketing de destino, bem como a competitividade e o sucesso a longo prazo do destino" (Wang \& Krokover, 2008, p. 2).

A cooperação entre empresas já é vista em ações conhecidas como Co-marketing, que surge do inglês “Cooperative Marketing” e que Diaz et al. (2013) retratam "como o acordo de colaboração entre duas ou mais marcas, empresas ou instituições para desenvolver um produto ou serviço que gera resultados benéficos para as diferentes partes que compõem o contrato de colaboração" (Diaz et al, 2013, p. 4)

Os mesmos autores ressaltam que esta cooperação pode ser trabalhada de diferentes formas, sendo uma delas, em que as empresas não são diretamente concorrentes, chamada de cooperação vertical, que une variados empreendimentos de níveis diferentes da mesma cadeia de valores. Já uma outra forma, de cooperação horizontal, une variadas empresas que estão no mesmo nível da cadeia de valores, ou seja, podendo ser conhecidas como concorrentes diretas 
Perinotto, A. R. C., Lima Sobrinho, L. de. Soares, J. R. R., \& Sánchez Fernandéz, M. D. (2021, maio/ago.). O uso das estratégias de Co-marketing, Coopetição e marketing do destino, por meio da mídia social Instagram no período de pandemia

(Diaz et al, 2013). Em ambas as formas existe uma relação de cooperação entre as empresas, porém existindo um estudo mais aprofundado quando tratado das empresas concorrentes, que acabam competindo entre si pelo mesmo mercado.

Merofa \& Bueno (2009) justificam que as situações em que empresas competem e cooperam entre si são visando o aumento de vantagens competitivas, tendo tais ações se tornado frequente devido a complexidade e dinamismo do ambiente competitivo. Somado a isto, reforçam que para o sucesso empresarial diante de um ambiente complexo, é importante que as empresas utilizem de estratégias competitivas e cooperativas simultaneamente, o que abre espaço para o surgimento da "coopetição", fenômeno este estudado pela academia, um neologismo que combina as palavras "competição" e "cooperação" (Merofa \& Bueno, 2009).

Sobre esse conceito, Wang e Krokover (2008) comentam sobre a complexidade das relações de coopetição, por consistir em duas lógicas de interação diametralmente diferentes, a cooperação e competição, tendo como complemento em suas ideias, a fala de Bengtsson e Kock (1999), citado por Leão (2005), na afirmação de que a coopetição é o tipo de relação mais importante, visto que as empresas, no cenário da cooperação, se ajudam buscando um desenvolvimento mútuo e, no cenário da competição, pressionam-se mutuamente na busca pelo desenvolvimento.

Merofa e Bueno (2009) ao citarem Dagnino e Padula (2002), destacam a formação de um novo sistema de criação de valor com a coopetição, surgindo a partir de um novo tipo de interdependência estratégica entre empresas que se desenvolve em uma base de interesses parcialmente convergentes, em que por um lado cooperam para conseguir posicionar-se no mercado e por outro, concorrem para dividi-lo, ser a escolha do cliente (Brandenburger e Nalebuff, 1996).

Ao resumo de que a Coopetição é de uma forma geral compreendida como a cooperação entre concorrentes e mesmo sendo um conceito recente, em que a maioria de seus estudos estando concentrado em setores de ponta, intensivos em tecnologia, a utilização deste novo conceito é aplicável a qualquer setor da economia (Leão, 2005).

Sabe-se que "as empresas de turismo envolvidas na coopetição estão envolvidas em um relacionamento que, por um lado, consiste em concorrência devido a interesses conflitantes e, por outro lado, consiste em cooperação devido a interesses comuns” (Wang \& Krokover, 2008). Esta mentalidade já vem sendo bem absorvida por partes interessadas do turismo ao abordarem a questão do marketing de destino, no qual se sabe da existência de características favoráveis para formação de redes de coopetição. Nesta rede, trabalha-se a cooperação entre os 
Perinotto, A. R. C., Lima Sobrinho, L. de. Soares, J. R. R., \& Sánchez Fernandéz, M. D. (2021, maio/ago.). O uso das estratégias de Co-marketing, Coopetição e marketing do destino, por meio da mídia social Instagram no período de pandemia

concorrentes visando uma eficácia na comercialização do produto turístico, causando posteriormente a melhora na competitividade do destino em nível regional, nacional e internacional.

Assim, no contexto turístico, é muito comum a formação de alianças de organizações do turismo, como associações de turismo local e regional e também de outras alianças de marketing feitas por organizações de destino local (Wang \& Krokover, 2008), havendo somente a necessidade de uma visão macroeconômica para que se concentre na vantagem competitiva do destino.

Assim, para o novo empreendimento que se deseja implantar, tais estratégias são vistas com grande relevância, visto que, mesmo sendo estratégias muito trabalhadas em maior medida por grandes empresas, a tendência é que cada vez mais pequenas e médias empresas às utilizem sabendo que as alianças podem resultar em muitos benefícios visando a superação de obstáculos existente para elas (Diaz et al, 2013).

\section{Procedimentos metodológicos}

Partindo dos conceitos que foram expostos neste trabalho, optou-se como metodologia de pesquisa de imersão na internet com cunho qualitativo, Gondima (2020) para trazer um estudo qualitativo que se utiliza das comunidades virtuais para a realização de pesquisas e se valendo "da capacidade de rastrear dados contidos na internet" (Alves, 2017, p. 10). Ademais, como destaca Ferreira (2012), esta técnica permite acesso contínuo aos informantes, por isso é mais rápida e menos dispendiosa que outros métodos. Finalmente, tem sido um método em crescimento quanto a sua utilização pelos estudiosos do turismo, quando estes buscam analisar interações on-line nas comunidades virtuais (Gondima, 2020).

Assim, para se chegar ao objetivo, o processo metodológico foi dividido em quatro etapas. A primeira etapa foi realizar um levantamento bibliográfico para a fundamentação teórica dos conceitos importantes do trabalho, como: Tecnologia de comunicação e informação (TIC), mídias sociais, marketing digital, coopetição, marketing de destino, co-marketing. Posterior a isto foi feito um levantamento dos empreendimentos que seriam utilizados como amostra no estudo. Para isto foi utilizado o CADASTUR - Sistema Nacional de Cadastro dos Prestadores de Serviços Turísticos, sendo este um sistema on-line de cadastro de empresas e profissionais do setor de turismo por iniciativa do Ministério do Turismo. Buscou-se neste sistema pela atividade "Meios de Hospedagem" no município de Jijoca de Jericoacoara no 
Perinotto, A. R. C., Lima Sobrinho, L. de. Soares, J. R. R., \& Sánchez Fernandéz, M. D. (2021, maio/ago.). O uso das estratégias de Co-marketing, Coopetição e marketing do destino, por meio da mídia social Instagram no período de pandemia

Estado do Ceará no qual foram encontrados 194 estabelecimentos de hospedagem cadastrados. A terceira etapa se deu através de pesquisa na mídia social Instagram buscando quantas dessas empresas encontradas possuíam um "perfil". Como referência para busca utilizou-se o nome encontrado no sistema do CADASTUR como "Nome Comercial / Fantasia", sendo necessário algumas variações no nome de referência no momento da pesquisa na mídia social, visto que nem sempre se encontrava o perfil do empreendimento na primeira tentativa. Ao final, dessa etapa, constatou-se 129 estabelecimentos de hospedagem do município de Jijoca de Jericoacoara presentes com um perfil na mídia social e que serviram como amostra para este trabalho. Na quarta e última etapa foram observadas as publicações realizadas pelas 129 empresas em seus perfis durante o período de pandemia, considerado para este trabalho as publicações realizadas entre os dias 17 de março e 06 de julho de 2020, contabilizando um total de 112 dias. Foi estipulado o dia 17 de março por ser o dia seguinte ao primeiro decreto estadual relacionado ao COVID-19, e o dia 06 de julho, por este ser o dia de realização das pesquisas na mídia social.

Para cada publicação contida no perfil do estabelecimento, concentrou-se a observação em dois pontos: tipo de publicação e se haviam citações com o símbolo “@” ou marcação de outro usuário nas publicações realizadas pelo estabelecimento. Os tipos de publicações foram caracterizados em Foto/Imagem/Vídeo de: Destino; Empreendimento NÃO concorrente; Empreendimento concorrente; Próprio empreendimento; Outros. Já as citações foram categorizadas em: Citação do destino; Citação de NÃO concorrente; Citação de concorrente. Essa categorização surgiu ao longo do percurso da pesquisa, sem haver previamente uma caracterização por busca específica por estes temas.

\section{Apresentação e análises dos resultados e análises}

Para todos os 129 empreendimentos, foi investigado o teor de suas publicações, que estão relacionadas a fotos, imagens ou vídeos postados no perfil. Isso porque a gestão da comunicação é um dos pilares que as organizações tem que trabalhar em um momento de crise González-Herrero (1998). Neste sentido, investigou-se como o tecido empresarial do destino estudado se comunicava na mídia digital Instagram durante o período inicial da crise causada pela COVID-19. Isto é, quando o mundo inteiro permanecia fechado, e, portanto, a atividade turística estava impossibilitada de ocorrer. Assim, ao acessar o link "publicações” dos perfis, foi inicialmente contabilizados quantas publicações (fotos/imagens/vídeos) foram realizadas 
Perinotto, A. R. C., Lima Sobrinho, L. de. Soares, J. R. R., \& Sánchez Fernandéz, M. D. (2021, maio/ago.). O uso das estratégias de Co-marketing, Coopetição e marketing do destino, por meio da mídia social Instagram no período de pandemia

pelo estabelecimento no período estipulado. Ainda que pareça que se vai "quantificar" as publicações, o intuito inicial era simplesmente identificar se houve labor de comunicação por parte das empresas nesse período de crise.

Percebeu-se que uma grande parte das empresas encontradas no Instagram publicaram algo neste período de pandemia, contabilizando 93 estabelecimentos. Totalizando um total de 1.985 publicações. Nesse primeiro momento já foi possível identificar que as postagens perseguiam o objetivo de seguir posicionando o destino. Isto porque o teor das mensagens não buscava a interação comercial, vender. Mais que perseguir uma venda (mesmo que em futuro), as postagens comunicavam aspectos do lugar, perseguindo manter-se presentes no imaginário do potencial turista. Para efeito de análise deste trabalho quanto ao marketing do destino, marketing colaborativo ou coopetição, as publicações foram caracterizadas em Foto/Imagem/Vídeo de: Destino; Empreendimento NÃO concorrente; Empreendimento concorrente; Próprio empreendimento; Outros (referentes a dia das mães, dia dos namorados, pessoas, entre outras publicações que não se encaixasse em alguma caracterização anterior).

A Figura 1 mostra um gráfico com a relação do número de estabelecimentos quanto ao tipo de publicação realizada.

Figura 1 - Número de estabelecimentos quanto ao tipo de publicação

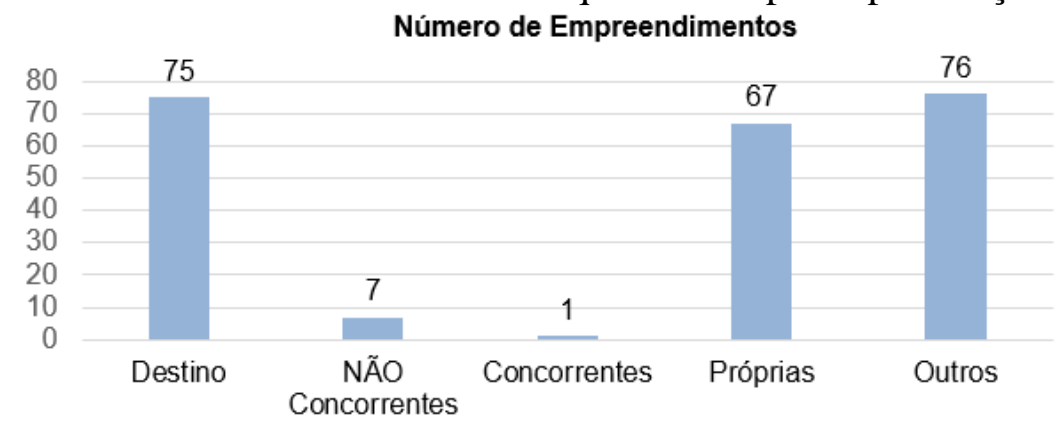

Fonte: Autores.

Com esses resultados, observa-se um elevado número de empreendimentos que procuraram divulgar o destino, seus próprios estabelecimentos e outros conteúdos. Neste tipo de postagens encontram-se desde mensagens de esperança, dando ânimo ao mundo pelo fim desta situação tão impactante na saúde e economia das pessoas, como mensagens que utilizam o sentimento de saudade para mostrar as belezas do lugar e gerar engajamento com os seguidores. Assim, nossos resultados são corroborados pelos resultados de González-Herrero (1998), indicando que em tempos de crise a comunicação deve servir para esclarecer e corrigir, minimizar as consequências do problema gerador da crise e, como não, posicionar. 
Perinotto, A. R. C., Lima Sobrinho, L. de. Soares, J. R. R., \& Sánchez Fernandéz, M. D. (2021, maio/ago.). O uso das estratégias de Co-marketing, Coopetição e marketing do destino, por meio da mídia social Instagram no período de pandemia

Cabe destacar que a diferença de outras crises, como podem ser as econômicas ou reputacionais, a crise derivada da pandemia da COVID-19 tem uma particularidade que deve ser destacada: ela parou o mundo. Em outras crises, a organização deve trabalhar para recuperar um mercado perdido (ou que pode perder) para os seus competidores. Porém, no caso de uma pandemia mundial que recorta a mobilidade e impossibilita as relações sociais que caracterizam o funcionamento do setor turístico, entende-se que buscar a interação monetária seria um erro por parte das empresas. E esses resultados vem a fundamentar esta conjectura. Os estabelecimentos estudados (todos os que geraram publicação durante o fechamento obrigatório de negócios e diminuição da interação social) demonstraram que seria mais benéfico adaptar a sua comunicação para o posicionamento que para a venda.

Quando se observou a estratégia de co-marketing e coopetição, percebe-se um baixo número de meios de hospedagem que realizam esta estratégia, tendo somente 7 estabelecimentos que publicaram fotos/imagens/vídeo de outro empreendimento e sendo estes não concorrentes. Porém, cabe ressaltar que se buscou investigar essas interações desde uma perspectiva qualitativa, buscando identificar como e o que comunicavam. Sendo assim, vê-se benéfico para o destino que o tecido empresarial utilize este tipo de estratégia, dado que gera uma ideia de complementariedade necessária para que o destino funcione. Identificou-se postagens de empresas (alojamento, por exemplo) que marcavam outras colaboradoras (marcas de biquínis, lojas de alimentação, esportes radicais, restaurantes ou fotógrafos, por exemplo). Dado o funcionamento da própria plataforma Instagram, realizar esse tipo de publicação aumenta o engajamento do perfil e melhora a visibilidade da postagem. Além disso, no imaginário do potencial turista ficará presente que, em Jericoacoara, neste caso, ele terá acesso a muitos serviços complementários durante a sua estadia.

Ao avaliar o quantitativo de publicações realizadas pelos 93 empreendimentos e relacioná-los com a caracterização proposta, encontrou-se os dados especificados na Figura 2. 
Perinotto, A. R. C., Lima Sobrinho, L. de. Soares, J. R. R., \& Sánchez Fernandéz, M. D. (2021, maio/ago.). O uso das estratégias de Co-marketing, Coopetição e marketing do destino, por meio da mídia social Instagram no período de pandemia

Figura 2 - Tabela e gráfico que relacionam o quantitativo de publicação realizada pela caracterização proposta

\begin{tabular}{|l|c|}
\hline \multicolumn{2}{|l|}{ Número de Publicaçöes } \\
\hline Destino & 1008 \\
\hline $\begin{array}{l}\text { NÄO } \\
\text { Concorrentes }\end{array}$ & 17 \\
\hline Próprias & 562 \\
\hline Concorrentes & 1 \\
\hline Outros & 397 \\
\hline Total & $\mathbf{1 9 8 5}$ \\
\hline
\end{tabular}

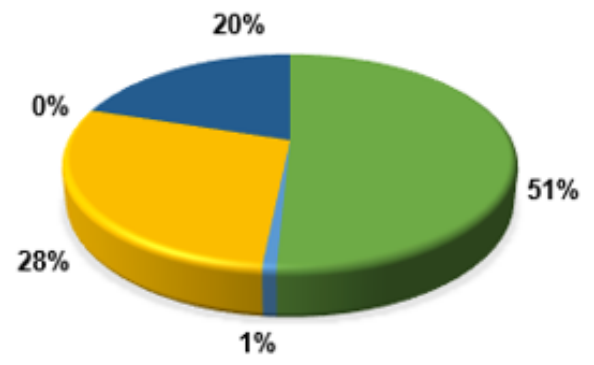

a Destino

a NÄO Concorrentes

aPróprias

a Concorrentes

Outros

Fonte: Autores.

Para empreendimentos concorrentes, do mesmo nível da cadeia produtiva, somente um empreendimento postou algo. Percebe-se assim, uma estratégia bem forte quanto ao marketing de destino, visto que um pouco mais da metade das publicações foi realizado com foco no destino Jericoacoara, tendo como segundo foco de marketing, o próprio estabelecimento, seguido de outros conteúdos. Neste sentido, identificam-se estratégias de coopetição com relação ao posicionamento do destino, isto é, estes atores do setor turístico atuam para melhorar a presença do destino em internet. Porém, poucos empreendimentos realizam estas estratégias diretamente com os seus concorrentes.

Ao entender que as estratégias de marketing em análise neste trabalho podem ser realizadas na mídia social Instagram através das publicações e a partir das citações nestas publicações, foram analisadas as citações realizadas pelos 93 empreendimentos que publicaram algo. Com isso, na investigação das publicações dos estabelecimentos, encontrou-se que 40 estabelecimentos fizeram algum tipo de citação em suas publicações, dentro das categorias apresentadas na metodologia: Citação do destino (perfil da prefeitura, perfil de alguma associação, perfil criado para divulgação do destino como: @jericoacoara, entre outros); Citação de NÃO concorrente; Citação de concorrente. Desta forma ressalta-se o que Fumi Chim-Miki \& Batista-Canino (2016) colocam da importância da coopetição para o turismo quando dizem que:

a coopetição é vista como um constructo que representa o comportamento intrínseco do setor turístico, cujas empresas se complementam para formar um mercado, mas simultaneamente competem pela divisão dele. A existência de uma meta comum de desenvolver o destino é o maior indutor da coopetição, ocasionando a inseparabilidade entre a cooperação e a concorrência (Fumi Chim-Miki \& Batista-Canino, 2016, p. 3). 
Perinotto, A. R. C., Lima Sobrinho, L. de. Soares, J. R. R., \& Sánchez Fernandéz, M. D. (2021, maio/ago.). O uso das estratégias de Co-marketing, Coopetição e marketing do destino, por meio da mídia social Instagram no período de pandemia

Assim, menos da metade dos estabelecimentos realizou essa estratégia de divulgação. Ainda, pode-se observar que dentre os 40 estabelecimentos (43\% do total) que fizeram alguma citação em suas publicações, houve uma boa ação de co-marketing, visto que 33 citaram estabelecimentos de não concorrentes, ou seja, presentes na cadeia do turismo de Jericoacoara e não sendo meio de hospedagem (por exemplo).

Além disso, pode-se dizer que as citações também foram bem utilizadas para uma ação de coopetição, tendo 8 meios de hospedagem citado um concorrente. Com repetições de postagens constantes ao longo do período da pesquisa entre empresas concorrentes se utilizando de hashtags e de marcações dos perfis dos concorrentes nas postagens. Neste sentido, entendese que estas estratégias de comunicação desempenhadas pelos estabelecimentos turísticos de Jericoacoara estão em linha com o apresentado por González-Herrero (1998), quem indica que nos tempos de crise deve-se oferecer ao potencial produtos capazes de satisfazer as suas necessidades hedonistas, portanto faz-se necessário minimizar os fatores de risco e melhorar a imagem do produto turístico. Importante salientar que as coletas e período da pesquisa se deram no início da pandemia no Brasil, entre os meses de março e abril de 2020, momento este que ainda existiam fluxos turísticos relevantes para o Nordeste do Brasil, com algumas restrições sanitárias.

Ao relacionar agora o quantitativo de citações realizadas pelos 40 empreendimentos com as três categorias de análise, obtêm-se os dados apresentados na Figura 3, em que se observa muitas citações de empreendimentos não concorrentes quando comparados às outras duas categorias, estando em segundo as citações de empreendimentos concorrentes, reforçando o que foi comentado no parágrafo anterior quanto a utilização das citações para realização das estratégias de co-marketing e coopetição. Isto é, nesse destino percebe-se a presença das estratégias coopetitivas, ou ganha-ganha, como destacam Brandenburger e Nalebuff (1996), indicando que todos os envolvidos no mercado ganham nesse tipo de atuações. 
Perinotto, A. R. C., Lima Sobrinho, L. de. Soares, J. R. R., \& Sánchez Fernandéz, M. D. (2021, maio/ago.). O uso das estratégias de Co-marketing, Coopetição e marketing do destino, por meio da mídia social Instagram no período de pandemia

Figura 3 - Tabela e gráfico que relacionam o quantitativo de citações com as categorias estabelecidas

\begin{tabular}{|l|c|}
\hline \multicolumn{2}{|l|}{ Número de Citações (@.....) } \\
\hline Destino & 37 \\
\hline $\begin{array}{l}\text { NÃO } \\
\text { Concorrente }\end{array}$ & 246 \\
\hline Concorrente & 64 \\
\hline Total & $\mathbf{3 4 7}$ \\
\hline
\end{tabular}

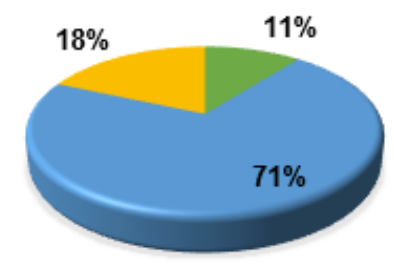

aDestino

\NÄO Concorrente

aConcorrente

Fonte: Autores.

Deste trabalho pode-se retirar que das 246 citações de estabelecimentos não concorrentes, mostrado na Figura 3, 177 delas (72\%) foram realizadas por estabelecimento com mais de 10.000 seguidores, que são apenas 19 estabelecimentos dentro do total de 93 . Ou seja, só os 19 meios de hospedagem que possuem mais de 10.000 seguidores, fizeram $72 \%$ das citações identificadas na pesquisa, deixando evidente que os meios de hospedagem que possuem mais seguidores provavelmente realizam mais parcerias na divulgação de marcas de empresas não concorrentes, possibilitando maior visualização das marcas do destino. Finalmente, um aspecto que merece bastante destaque é o fato de que essas iniciativas comunicacionais tenham partido dos próprios estabelecimentos, sem que tenha sido uma estratégia de posicionamento do destino desenhada pelos gestores do turismo da região. Esse é um aspecto muito destacável porque demonstra que a comunidade local, nesse caso os empreendedores do lugar assumem um papel de coparticipação no êxito do destino. Se bem é certo que o mundo parou por um tempo em decorrência dos confinamentos obrigatórios derivados da pandemia da COVID-19, nem todas as empresas foram capazes de reagir tão rapidamente e adaptar a sua comunicação. No próprio destino em questão identificou-se que algumas empresas da Vila de Jericoacoara estiveram mais de 3 meses sem comunicar nada através da sua rede Instagram. Porém, ações como essas identificadas aqui nesse trabalho permitiram o destino seguir posicionado no imaginário do potencial turista. Assim, uma evidência para esse resultado é corroborada por ViajaNet (2021), quem indica que Jericoacoara está entre os 10 destinos mais buscados em google por internautas em fevereiro de 2021. 
Perinotto, A. R. C., Lima Sobrinho, L. de. Soares, J. R. R., \& Sánchez Fernandéz, M. D. (2021, maio/ago.). O uso das estratégias de Co-marketing, Coopetição e marketing do destino, por meio da mídia social Instagram no período de pandemia

\section{Considerações finais}

Como principal conclusão, entende-se que este trabalho oferece uma resposta ao primeiro questionamento levantado por Xifras (2020), em que o autor destacava a necessidade de investigar como atuou a comunicação das organizações implicadas na crise. Fica, portanto, uma oportunidade para oferecer resposta ao segundo questionamento, como essa atuação afetou a sua reputação.

O presente estudo fornece várias implicações importantes para a gestão da comunicação em turismo através de estratégias de coopetição e co-marketing. Em primeiro lugar, estas conclusões revelam que estratégias de coopetição e co-marketing não são positivas somente para as empresas que as implementam. Isto é, uma comunicação neste sentido impacta positivamente no posicionamento do destino receptor, que ao fim e ao cabo, acabará por impactar no seguimento do turismo na região após a crise ter acabado. As descobertas oferecem às empresas do setor turístico insights inestimáveis no estabelecimento de suas estratégias comunicativas na comunidade online, uma vez que delas dependerá o posicionamento do destino turístico. Assim mesmo, uma vez que os turistas se interessem pelo destino, necessitarão decidir pelas empresas do trade onde contratarão os serviços (alojamento, restauração, serviços complementares ao turismo), portanto, esta colaboração competitiva posicionará também estas empresas.

Em segundo lugar, a análise das publicações revela que os destinos turísticos são os beneficiados das estratégias de coopetição e co-marketing, isso porque eles são os grandes referenciados polos estabelecimentos. Neste sentido, notando que as empresas parecem temer criar vínculos com outras organizações por meio das suas redes sociais, percebe-se como fundamental a necessidade dos próprios gestores nos destinos turísticos trabalharem para que as empresas colaborem entre si, afinal, a médio e longo prazo, o resultado seria positivo para todos os stakeholders. Ainda, revelou-se que proporcionar o uso de estratégias de coopetição e co-marketing pode aumentar a credibilidade da informação encontrada na rede, dado que a publicação de uma empresa sobre uma outra funciona como uma recomendação para o cliente final, pois assim funciona o co-marketing.

Com os resultados obtidos e relatados anteriormente, pode-se dizer que um número considerável dos meios de hospedagem de Jijoca de Jericoacoara procurou se comunicar com seus seguidores, através de publicações na mídia social Instagram durante o período de pandemia. Isso fez com que o destino, foco principal na ação de marketing para o retorno das 
Perinotto, A. R. C., Lima Sobrinho, L. de. Soares, J. R. R., \& Sánchez Fernandéz, M. D. (2021, maio/ago.). O uso das estratégias de Co-marketing, Coopetição e marketing do destino, por meio da mídia social Instagram no período de pandemia

atividades pós pandemia, continuasse posicionado para os seguidores destes meios de hospedagem. Quanto aos que não realizaram nenhuma publicação, não se pode afirmar que estes não se relacionaram com seus clientes ou possíveis clientes na divulgação de variados conteúdos, podendo os estabelecimentos terem usado outras mídias sociais para isto.

O trabalho apresenta novas formas de estudar as ações em conjunto, por meio do marketing digital, se utilizando de uma metodologia de estudos de mídia digital, buscando dados qualitativos de assuntos que relacionem as empresas turísticas, neste caso em específico, tratando dos assuntos de coopetição e co-marketing, o que é de certo modo novidade no meio científico do Turismo Nacional.

Quanto a realização das estratégias de marketing abordadas ao longo deste trabalho, o marketing de destino, o co-marketing e a coopetição, observou-se a utilização das "publicações", sendo elas por meio de fotos, imagens ou vídeos, com maior foco para a realização de estratégias coopetitivas relacionadas ao marketing de destino. Essa evidência confirma-se no elevado número de publicações contendo paisagens do destino.

Para a realização do co-marketing e da coopetição, as "publicações" não foram de grande utilização, entretanto as citações demonstraram ser a melhor opção para realização dessas estratégias, principalmente do co-marketing, quando os meios de hospedagem citam empreendimentos não concorrentes como escolas de kitesurf, fotógrafos da região, passeios de bugre, entre outros.

A estratégia de coopetição, por mais que aconteça de maneira muito reduzida quando na divulgação de um empreendimento concorrente, ela fica mais patente na realização do marketing de destino. Isso tudo considerando o que foi exposto ao longo do trabalho quanto ao conceito deste tema, que inicialmente se tem uma ação de cooperação na busca do turista para o destino, para posteriormente ocorrer a competição entre os atores locais. Como estratégia a coopetição por meio do Instagram pode ajudar para que as publicações atinjam um maior público/ visualizações, com menos custo/ recursos (tempo, profissional), com publicações mais específicas sobre os empreendimentos.

Outra reflexão que também pode servir de base para futuros trabalhos é a relação entre os estabelecimentos que publicaram ou citaram algo com o número de seguidores que este possui em seu perfil na mídia social. Esta reflexão se faz relevante para futuras parcerias de novos empreendimentos, onde o número de seguidores do estabelecimento vai estar diretamente relacionado às possíveis visualizações da marca do novo empreendimento. 
Perinotto, A. R. C., Lima Sobrinho, L. de. Soares, J. R. R., \& Sánchez Fernandéz, M. D. (2021, maio/ago.). O uso das estratégias de Co-marketing, Coopetição e marketing do destino, por meio da mídia social Instagram no período de pandemia

Neste sentido é importante entender a coopetição e o co-marketing nas empresas de turismo, seja em qualquer destino, como fundamental para traçar planos de ações de estratégias macro, em termos de destino turístico em geral para que juntos possam sair das crises de baixa demanda e de baixa captação de renda.

Acredita-se que a pesquisa indiretamente ampliou a compreensão sobre as mídias sociais e o turismo, e para uma melhor abrangência dos resultados, a partir deste estudo, é recomendada a reaplicação deste procedimento de pesquisa com maior abrangência do recorte temporal de postagens dos perfis e a ampliação para outros perfis similares do setor de turismo. Em face ao desvendado, se aconselha também que em pesquisas futuras se debrucem em averiguar qualitativamente as publicações nas mídias sociais realizadas por estas empresas abrangendo a discussão aqui iniciada do marketing digital. É possível, portanto, identificar o tipo destas publicações, dadas as diversas possibilidades de conteúdo no Instagram.

Além disso, conclui-se que o Instagram fornece elementos que, sendo sistematizados, podem ser aproveitados no planejamento de estratégia de marketing dos destinos turísticos. Até mesmo por meio da percepção crítica dos consumidores-turistas, nos comentários e nas postagens das empresas, deste modo, ampliando a relação do marketing digital da oferta para a demanda, expandindo a possibilidade de compreender aquilo que lhes agradam ou não, ou ainda os pontos fortes e fracos do que está sendo analisado. Desta forma, seria possível elaborar estratégias de marketing a partir das singularidades de cada destino.

\section{Referências}

Alves, F. G.; Costa, H. S.; \& Perinotto, A. R. C. (2017). Instagram como ferramenta para fidelização de clientes: Fotografia, Redes Sociais e Turismo. Marketing \& Tourism Review, Belo Horizonte, MG, Brasil, v. 2, n. 2, dezembro, 2017. Disponível em: https://revistas.face.ufmg.br/index.php/mtr/article/view/4562/pdf.

Barbosa, L. G. M.; Coelho, A. M.; Motta, F. A. T.; Guimarães, I. L. B.; \& Guimarães, T. (2020). Impacto Econômico do Covid-19 - Propostas para o Turismo Brasileiro. Edição 1. Abril/2020. Centro de Estudos em Competitividade da FGV/EBAPE. Disponível em: https://fgvprojetos.fgv.br/sites/fgvprojetos.fgv.br/files/01.covid19_impactoeconomico_v09 compressed_1.pdf.

Brandenburger, A.; \& Nalebuff, B. (1996). Co-opetition. Nova York: Crown Publishing Group, 1996.

Buosi, M. C. De A.; \& Silva, A. L. L. Da. (2013). A Avaliação dos Atributos da Imagem e sua Relação com a Imagem Global do Destino de Turismo Internacional - Praia de Jericoacoara. 
Perinotto, A. R. C., Lima Sobrinho, L. de. Soares, J. R. R., \& Sánchez Fernandéz, M. D. (2021, maio/ago.). O uso das estratégias de Co-marketing, Coopetição e marketing do destino, por meio da mídia social Instagram no período de pandemia

Revista Turismo em Análise, USP, São Paulo/SP. Vol. 24, n. 1, abril 2013. 2013. Disponível em: https://doi.org/10.11606/issn.1984-4867.v24i1p25-40.

Costa-Sánchez, C.; López-García, X. (2020). Comunicación y crisis del coronavirus en España. Primeras lecciones. El profesional de la información, v. 29, n. 3, e290304. https://doi.org/10.3145/epi.2020. may.04.

Diaz, F. T.; Sanjuán, F. J. L.; Tortosa, R. L.; Nadal, C. B.; \& Varón, D. J. (2013). Co-marketing como hierramienta estratégica empresarial. Revista de investigación, Universitat Politècnica de València. Disponível em: https://riunet.upv.es/bitstream/handle/10251/50074/Torreblanda\%20D\%C3\%ADaz\%2C\%2 0F.\%20-\%20Co.Marketing\%20como.pdf?sequence=1\&isAllowed=y.

Ferrer-Serrano, M.; Latorre-Martínez, M.-P.; \& Lozano-Blasco, R. (2020). Universidades y comunicación. Papel de Twitter durante el inicio de la crisis sanitaria de la Covid19. Profesional De La Información, 29(6). https://doi.org/10.3145/epi.2020. nov.12.

Ferreira, N. S.; \& Arruda, E. J. M. Filho (2012). Preferência e usabilidade da imagem social no Facebook: uma análise netnográfica. XV Seminário em Administração. Out/2012. Disponível em: http://sistema.semead.com.br/15semead/resultado/trabalhosPDF/5.pdf.

Fumi Chim-Miki, A.; \& Batista-Canino, R. M. (2016). A pesquisa sobre coopetição: em direção a uma melhor compreensão do construto e sua aplicação no turismo. Turismo - Visão e Ação, vol. 18, núm. 3, set/dez, 2016, pp. 424-447. Universidade do Vale do Itajaí, Camboriú, Brasil. Disponível em: http://www.redalyc.org/articulo.oa?id=261056061002.

Gama, R. B. Neto (2020). Impactos da COVID-19 sobre a economia mundial. Boletim de Conjuntura (BOCA), ano II, vol. 2, n. 5, Boa Vista, Roraima, 2020. Disponível em: https://revista.ufrr.br/boca/article/view/RicardoBorges.

Gonçalves, M. B.; Guardia, M. S.; \& Guardia, S. R. (2012). As mídias sociais no marketing turístico: um estudo sobre seu uso na promoção do roteiro de Seridó. Carpe Diem: Revista Cultura e Científica do UNIFACEX. v. 10, n. 10, 2012. Natal/RN. Disponível em: https://periodicos.unifacex.com.br/Revista/article/view/204.

Gondima, C. B.; Bolzánb, R. E.; Espínolac, R. S.; \& Alexandred, M. L. O. (2020). Netnografia como método de pesquisa em turismo: análise de estudos de Pós-graduação no Brasil. Revista Turismo em Análise - RTA/ECA/USP. v. 31, n. 1, p. 19-36, jan./abr., 2020. Disponível em: http://www.revistas.usp.br/rta/article/view/160658.

González-Herrero, A. (1998). Comercialización de productos y planificación de crisis en el sector turístico imagen corporativa y marketing centrado en el consumidor. Papers de Turisme, ISSN 0214-8021. Impresso. v. 24, 6-45.

Gössling, S.; Scott, D.; \& Hall, C. M. (2020): Pandemics, tourism and global change: a rapid assessment of COVID-19, Journal of Sustainable Tourism. Disponível em: https://doi.org/10.1080/09669582.2020.1758708. 
Perinotto, A. R. C., Lima Sobrinho, L. de. Soares, J. R. R., \& Sánchez Fernandéz, M. D. (2021, maio/ago.). O uso das estratégias de Co-marketing, Coopetição e marketing do destino, por meio da mídia social Instagram no período de pandemia

Gretzel, U.; Fuchs, M.; Baggio, R.; Hoepken, W.; Law, R.; Neidhardt, J.; Pesonen, J.; Zanker, M.; \& Xiang, Z. (2020) e-Tourism beyond COVID-19: a call for transformative research. Springer-Verlag GmbH Germany, part of Springer Nature 2020, Information Technology \& Tourism. Disponível em: https://doi.org/10.1007/s40558-020-00181-3.

Huertas, Assumpción; Oliveira, Andrea; \& Girotto, Michele. (2020) Gestión comunicativa de crisis de las oficinas nacionales de turismo de España e Italia ante la Covid-19 // Crisis communication management by the national tourist organizations of Spain and Italy in the face of Covid-19. Profesional de la información, 2020, vol. 29, n. 4. Disponível em: https://doi.org/10.3145/epi.2020.jul.10.

Imme, A. (2020). Ranking das redes sociais: as mais usadas no Brasil e no mundo, insights e materiais gratuitos. Disponível em: https://resultadosdigitais.com.br/blog/redes-sociaismais-usadas-no-brasil/.

Lapolli, M.; Amaral, R.; Amaral, R. D. R. A.; \& Gauthier, F. Á. O. (2009). Tecnologias da informação e da comunicação como suporte à publicidade na era digital (Cap. 2, pp. 20-30). Em Maria Jose Baldessar, M. J., Comunicação multimídia: objeto de reflexão no cenário do século 21. Florianópolis, SC: Editora:NTDI/CCE/UFSC.

Leão, D. A. F. S. (2005). Relevância da Teoria da Coopetição para a Compreensão da Dinâmica dos Relacionamentos entre Empresas Concorrentes. Disponível em: http://www.anpad.org.br/admin/pdf/3es2005-476.pdf.

Lichtenheld, A. F.; Duarte, C. V.; \& Bortolon, A. (2018). O Instagram como estratégia de marketing digital: uma pesquisa ação na wood lanches. Disponível em: https://multivix.edu.br/wp-content/uploads/2018/12/o-instagram-como-estrategia-demarketing-digital-uma-pesquisa-acao-na-wood-lanches.pdf.

Meira, J. V. S; Araújo, J. V. N.; Bordignon, L. F.; \& Dos Anjos, S. J. G. (2017). Atributos relacionados à satisfação dos turistas e à intenção de retorno: um estudo em Jericoacoara/CE. TURyDES - Revista de investigación en turismo e desarrollo local, Málaga/Espanha. Vol. $10, \mathrm{~N}^{\mathrm{o}} 22.2017$.

Mendonça, F. (2020). Setor de Turismo no mundo cresceu 4\% em 2019, segundo OMT. Recuperado: 15/06/2020, Disponível em: http://turismocompartilhado.com.br/setor-deturismo-no-mundo-cresceu-4-em-2019-segundo-a-omt/.

Merofa, A.; \& Bueno, C. F. (2009). Coopetição: Uma análise teórica. IV Encontro de Estudos em Estratégias, Recife, 21-23-jun/2009. Disponível em: http://www.anpad.org.br/admin/pdf/3Es365.pdf.

Oliveira, J. E. S.; Resende, M. G. (n.d.) As mudanças no turismo com o advento da tecnologia de informação. Revista Eletrônica de Iniciação Científica RIC - Cairu. Salvador, BA. Disponível

em: https://www.cairu.br/riccairu/pdf/artigos/10\%20AS\%20MUDANCAS\%20NO\%20TURIS MO\%20COM\%200\%20ADVENTO\%20DA\%20TECNOLOGIA\%20DE\%20INFORMAC AO.pdf. 
Perinotto, A. R. C., Lima Sobrinho, L. de. Soares, J. R. R., \& Sánchez Fernandéz, M. D. (2021, maio/ago.). O uso das estratégias de Co-marketing, Coopetição e marketing do destino, por meio da mídia social Instagram no período de pandemia

Park, D.; Kim, W. G. \& Choi, S. (2019). Application of social media analytics in tourism crisis communication, Current Issues in Tourism, vol. 22, n. 15, 18101824, DOI: https://doi.org/10.1080/13683500.2018.1504900.

Perinotto, A. R. C.; \& Siqueira, R. A. (2018). As novas tendências do marketing digital para o setor turístico. Turismo: Estudos \& Práticas (RTEP/UERN), Mossoró/RN, vol. 7, n. 2, pp 186-215. Disponível em: http://periodicos.uern.br/index.php/turismo/article/view/3192.

Pizeta, D. S.; Severiano, W. R.; \& Fagundes, A. J. (2016). Marketing Digital: A utilização das mídias sociais como canal de comunicação impulsionando a compra do consumidor. Revista Ambiente Acadêmico. v. 2, n. 1. Disponível em: https://multivix.edu.br/wpcontent/uploads/2018/04/revista-ambiente-academico-edicao-3-artigo-1.pdf.

Purohit, K. (2018). Digital Tourism: Importance of Digital Marketing in Travel Industry. Research Scholar, Department of EAFM, University of Rajasthan, Jaipur, Rajasthan. International Conference on Modern Management Strategies, E-commerce and Global Economy-In Indian Context, Jaipur, Rajasthan, India. 02-03 February, 2018. Disponível em: https://inspirajournals.com/uploads/Album/704121383.pdf.

Sampaio, P. C. (2013). O Instagram como instrumento de marketing no meio digital para empresas de moda: Estudo de caso das lojas Voga IL-Brand. Curso de Comunicação Social, Universidade Federal do Ceará, Fortaleza, CE. Disponível em: http://www.repositorio.ufc.br/bitstream/riufc/26609/1/2013 tcc_pcsampaio.pdf.

Serviço Brasileiro de Apoio às Micro e Pequenas Empresas. (2020). Impactos da pandemia da Covid-19 sobre o turismo: Confira algumas dicas sobre como seu negócio pode passar pela crise. Santa Catarina. Douglas Luís Três, Leandro Silveira Kalbusch, Jefferson Auri de Araújo \& Alan David Claumann. Junho/2020. Disponível em: https://atendimento.sebraesc.com.br/inteligencia/.

Sprandel, M. (2009). A Comunicação e o Marketing na Cibercultura (Cap. 1, pp. 13-19). Em Maria Jose Baldessar, M. J., Comunicação multimídia: objeto de reflexão no cenário do século 21. Florianópolis, SC: Editora:NTDI/CCE/UFSC.

Soares, J. R. R.; Gabriel, L. P. M. C.; \& Perinotto, A. R. C. (2019). A competitividade do turismo MICE em Galícia: um estudo comparativo com Catalunia e Madri. Revista Turismo Em Análise, 30(2), 307-326. https://doi.org/10.11606/issn.1984-4867. v30i2p307-326.

Toledo, G. L.; Valdés, J. A.; Pollero, A. C. (2002). Configuración Del turismo em El ambiente globalizado: estúdio de casos de clusters turísticos. Revista Turismo em Análise, São Paulo, 2002. Disponível em: https://doi.org/10.11606/issn.1984-4867.v13i1p90-104.

Torres, C. (2009). A bíblia do marketing digital: tudo o que você queria saber sobre marketing e publicidade na internet e não tinha a quem perguntar. São Paulo, SP: Novatec.

Xifra, J. (2020). Comunicación corporativa, relaciones públicas y gestión del riesgo reputacional en tiempos del Covid-19. El profesional de la información, v. 29, n. 2, e290220. https://doi.org/10.3145/epi.2020. mar.20. 
Perinotto, A. R. C., Lima Sobrinho, L. de. Soares, J. R. R., \& Sánchez Fernandéz, M. D. (2021, maio/ago.). O uso das estratégias de Co-marketing, Coopetição e marketing do destino, por meio da mídia social Instagram no período de pandemia

Wang, Y.; \& Krokover, S. (2008). Destination marketing: competition, cooperation or coopetition?. International Journal of Contemporary Hospitality Management, Vol. 20, No. 2, pp. 126-141. Disponível em: https://www.researchgate.net/publication/241910868.

World Tourism Organization (2020), UNWTO World Tourism Barometer, May 2020 - Special focus on the Impact of COVID-19 (Summary), UNWTO, Madrid, DOI: https://doi.org/10.18111/9789284421817.

ViajaNet (2021). Destinos mais procurados no Google, Ranking Agência ViajaNet. https://www.viajanet.com.br/ranking. 